\title{
Erinacine A-enriched Hericium erinaceus mycelium ameliorates Alzheimer's disease-related pathologies in APPswe/PS1dE9 transgenic mice
}

\author{
Tzeng Tsai-Teng ${ }^{1}$, Chen Chin-Chu², Lee Li-Ya², Chen Wan-Ping ${ }^{2}$, Lu Chung-Kuang ${ }^{3}$, Shen Chien-Chang ${ }^{3}$,
} Huang F. Chi-Ying ${ }^{1}$, Chen Chien-Chih ${ }^{4^{*}}$ and Young-Ji Shiao ${ }^{1,3,5^{*}}$

\begin{abstract}
Background: The fruiting body of Hericium erinaceus has been demonstrated to possess anti-dementia activity in mouse model of Alzheimer's disease and people with mild cognitive impairment. However, the therapeutic potential of Hericium erinaceus mycelia on Alzheimer's disease remains unclear. In this study, the effects of erinacine A-enriched Hericium erinaceus mycelia (HE-My) on the pathological changes in APPswe/PS1dE9 transgenic mouse model of Alzheimer's disease are studied.

Results: After a 30 day oral administration to 5 month-old female APPswe/PS1dE9 transgenic mice, we found that HE-My and its ethanol extracts (HE-Et) attenuated cerebral A $\beta$ plaque burden. It's worth noting that the attenuated portion of a plaque is the non-compact structure. The level of insulin-degrading enzyme was elevated by both HE-My and HE-Et in cerebral cortex. On the other hand, the number of plaque-activated microglia and astrocytes in cerebral cortex and hippocampus were diminished, the ratio of nerve growth factor (NGF) to NGF precursor (proNGF) was increased and hippocampal neurogenesis was promoted after these administrations. All the mentioned benefits of these administrations may therefore improve the declined activity of daily living skill in APPswe/PS1dE9 transgenic mice.

Conclusions: These results highlight the therapeutic potential of HE-My and HE-Et on Alzheimer's disease. Therefore, the effective components of HE-My and HE-Et are worth to be developed to become a therapeutic drug for Alzheimer's disease.
\end{abstract}

Keywords: Alzheimer's disease, APPswe/PS1dE9 transgenic mice, Amyloid $\beta$, Neurogenesis, Erinacine A-enriched Hericium erinaceus mycelia, Insulin-degrading enzyme

\section{Background}

Alzheimer's disease (AD), an age-related progressive neurodegenerative disorder, is characterized by the formation of neurofibrillary tangles, extracellular aggregated amyloid- $\beta$ (A $\beta)$ plaques, and neural and synaptic loss [1]. The accumulation of $A \beta$ results in neuroinflammation and oxidative stress. $A \beta$ is a normal product of cellular metabolism derived from the amyloid precursor protein (APP) by the

\footnotetext{
* Correspondence: ccchen@sunrise.hk.edu.tw; yshiao@nricm.edu.tw

${ }^{4}$ Department of Biotechnology and Department of Nursing, HungKuang

University, Taichung 433, Taiwan, Republic of China

${ }^{1}$ Institute of Biopharmaceutical Science, National Yang-Ming University, Taipei

112, Taiwan, Republic of China

Full list of author information is available at the end of the article
}

successive action of the $\beta$ - and $\gamma$-secretases [2]. The accumulation of $A \beta$ in the brain is then determined by the rate of $A \beta$ generation versus clearance. Clearance can be accomplished via three major pathways: proteolytic degradation, microglia-mediated clearance, receptor-mediated transport across the blood-brain barrier [3].

Compromised neurogenesis presumably takes place earlier than onset of hallmark lesions or neuronal loss, and may play a role in the initiation and progression of neuropathology in AD [4]. Recent studies have shown that brain levels of nerve growth factor (NGF) precursor (pro-NGF) are increased in a stage dependent manner in AD [5], and NGF deprivation leads to cholinergic deficit, 
$\mathrm{A} \beta$ deposition, tau hyperphosphorylation and impaired neurogenesis [6, 7]. Moreover, inflammatory challenge triggered by $A \beta$ induces the production of proinflammatory cytokines by microglia as well as resident astrocytes have profound detrimental effects on adult neurogenesis [8]. Therefore, alteration of ratio of NGF/proNGF, inflammatory challenge and compromising neurogenesis are involved in the developments of AD.

Hericium erinaceus is an edible and medicinal mushroom with various pharmacological activities in the prevention of many age-associated neurological dysfunctions, including AD and Parkinson's disease [9]. Moreover, compounds isolated from its fruiting bodies and mycelia exhibit a potent activity to stimulate NGF expression and secretion in vitro and in vivo $[10,11]$. Recent studies demonstrated anti-dementia activity of its fruiting bodies in mice with cognitive deficits induced by $A \beta$ and in people with mild cognition impairment $[12,13]$. However, the anti-dementia activity of Hericium erinaceus mycelia remained unclear.

In the present study, we investigated the potentials of erinacin A-enriched Hericium erinaceus mycelia (HE-My) and it ethanol extracts (HE-Et) on AD-related pathologies in 5 month-old APPswe/PS1dE9 (APP/PS1) double transgenic mouse, a transgenic mouse model of AD expressing two mutations in the human APP as well as two human presenilin 1, exhibiting impaired exploratory behavior, spatial memory and synaptic function [14-16]. Our data suggests that HE-My and HE-Et ameliorated $A \beta$ plaques via increasing the level of insulin degrading enzyme (IDE) and microglia-mediated clearance. Additionally, HE-My and HE-Et also elevated NGF/proNGF ratio. All the alteration may result in promotion of neurogenesis and improving the decline of activity of daily living (ADL) skill.

\section{Methods}

\section{Sample preparation}

Hericium erinaceus (BCRC 35669) purchased from Bioresources Collection and Research Center (BCRC) in Food Industry Research and Development Institute (Hsinchu, Taiwan) were maintained and cultivated on potato dextrose agar at $26{ }^{\circ} \mathrm{C}$ for 15 days according to the method described earlier [17]. After incubation, a mycelial agar block $\left(1 \mathrm{~cm}^{3}\right)$ was removed, transferred to a 2-L Erlenmeyer flask containing $1.3 \mathrm{~L}$ synthetic medium (composed of $0.25 \%$ yeast extract, $4.5 \%$ glucose, $0.5 \%$ soybean powder, $0.25 \%$ peptone and $0.05 \% \mathrm{MgSO} 4$, adjusted to $\mathrm{pH} 4.5)$ and incubated for 5 days at $26{ }^{\circ} \mathrm{C}$ on a rotary shaker $(120 \mathrm{rpm})$. The fermentation process was then scaled up from a 2-L shake flask to $500-\mathrm{L}$ and 20-ton fermenters for 5 and 12 days, respectively. At the end of the fermentation process, the mycelia were then harvested, lyophilized, grounded into powder, and stored in a desiccator at room temperature (HE-My). The proximate composition analysis, including ash, total protein, lipids, and carbohydrates of the freeze-dried mycelia were determined according to official AOAC methods. The dry sample was then analyzed by UPLC to evaluate the content in the mycelia based on its dry weight. HE-My was extracted four times with $90 \%$ ethanol under reflux to give the ethanol extract (HE-Et). Their chemical finger prints were determined (Fig. 1). Three active components in HE-Et were identified and were compared to standards. The identification of erinacine A (HE-A), erinacine $\mathrm{C}(\mathrm{HE}-\mathrm{C})$ and erinacine $\mathrm{S}$ (HE-S) in HE-Et using NMR and LC-MS-MS have been previously described $[17,18]$. The HE-My (containing $19 \mathrm{mg} / \mathrm{g} \mathrm{HE}-\mathrm{A}$ ) and HE-Et (containing 104.4 mg/g HE-A) were dissolved in vehicle (3\% DMSO/10 \% cremophor EL (Sigma)/87.5 \% D5W (5 \% dextrose in water, pH 7.2) with vigorous shaking in order to get a final concentration of $3 \mathrm{mg} \cdot \mathrm{ml}^{-1}$ (HE-A) or $30 \mathrm{mg} \cdot \mathrm{ml}^{-1}$ (HE-My and HE-Et) before its administration to mice.

\section{Animal management and administration}

The Institutional Animal Care and Use Committee at the National Research Institution of Chinese Medicine approved the animal protocol (IACUC No: 100-A-04 and 102-417-3). The APPswe/PS1 $\triangle \mathrm{E} 9$ double transgenic mouse model (APP/PS1) of AD was purchased from Jackson Laboratory (No. 005864) that expressed a chimeric mouse/human APP695 harboring the Swedish K670M/ N671L mutations (APPswe) and human PS1 with the exon-9 deletion mutation (PS1 $\triangle \mathrm{E} 9$ ). Breeding gender ratio was a male with two females in one cage. Experiments were conducted using wild type (WT) siblings and AD transgenic female C57BL/6 J mice. The animals were housed under controlled room temperature $\left(24 \pm 1{ }^{\circ} \mathrm{C}\right)$ and humidity (55-65 \%) with 12:12 h (07:00-19:00) light-dark cycle. All mice were provided with commercially available rodent normal chow diet and water ad libitum.

To explore the effect of HE-My and HE-Et, 5 months old APP/PS1 mice were fed with HE-My and HE-Et (300 mg/kg/day) for 30 days for pathological test, and 5-bromo-2'-deoxyuridine (BrdU; Sigma) was injected intraperitoneally at $50 \mathrm{mg} / \mathrm{kg} /$ day at the last 7 days. For behavior test, 5 months old APP/PS1 mice were fed with HE-My (300 mg/kg/day) for 70-90 days.

\section{Tissue processing}

After administration by oral gavage to 5 month-old mice for 30 days, 5-bromo-2'-deoxyuridine (BrdU; Sigma) was injected intraperitoneally $(50 \mathrm{mg} / \mathrm{kg} /$ day $)$ at the last 7 days, then the mice were deeply anesthetized with chloral hydrate and then sacrificed by transcardial perfusion with saline at $\mathrm{pH}$ 7.4. Mice brain was removed and one hemisphere was homogenized in H-Buffer $(320 \mathrm{mM}$ sucrose, $2 \mathrm{mM}$ EDTA, $20 \mathrm{mM}$ Tris- $\mathrm{HCl}$ (pH 7.4), $1 \mathrm{mM}$ 




b
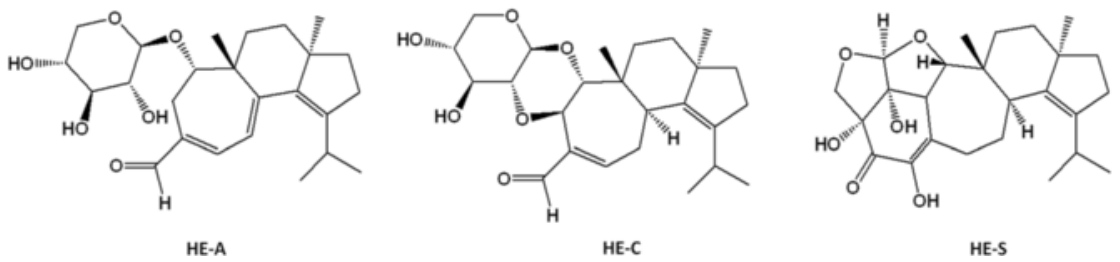

Fig. 1 The representative chemical finger prints and the structure of the major components of Hericium erinaceus mycelium. a. UPLC chromatogram of HE-Et was carried out on a Thermo syncronis C18 $(2.1 \times 100 \mathrm{~mm})$ column in Waters AcQuity Ultra Performance LC system with a diode array detector, monitored at $210 \mathrm{~nm}$. The mobile phase consisted of $0.1 \%$ phosphate water (a) and acetonitrile (b) using a gradient elution of $20-55 \%$ B at 0-2 $\min , 55-90 \%$ B at 2-9 min, 90-100\% acetonitrile at 9-10 min. The flow rate was $0.4 \mathrm{ml} / \mathrm{min}$. Three active components: HE-A, HE-C and HE-S were identified and compared to the standards, and their structure was shown in $\mathbf{b}$

PMSF, $5 \mu \mathrm{g} / \mathrm{ml}$ leupeptin, $5 \mu \mathrm{g} / \mathrm{ml}$ aprotinin) for $\mathrm{A} \beta$ ELISA and immunoblots. Another hemisphere was processed for histochemical and immunohistochemical staining. Dissected brains were immersed in $4 \%$ formaldehyde for $18 \mathrm{~h}$ at $4{ }^{\circ} \mathrm{C}$, then cryoprotected in sucrose before being sectioned into $30 \mu \mathrm{m}$ thick free-floating sections.

\section{Thioflavin S staining}

Thioflavin S (Ths; Sigma) is widely used to detect amyloid plaque deposition [19]. For triple immunofluorescent staining with thioflavin $S, A \beta$ plaque and microglia, dried sections were stained with fresh, filtered $1 \%$ thioflavin $\mathrm{S}$ in water for $60 \mathrm{~min}$, and then washed twice with $70 \%$ ethanol for 5 min each, twice with water for $2 \mathrm{~min}$ each, twice with PBS for 5 min each. The sections were then incubated in blocking buffer and antibody dilution buffer with corresponding antibodies, as mentioned above.

\section{Immunohistochemistry}

The mice were sacrificed by transcardial perfusion with saline at $\mathrm{pH}$ 7.4. One hemisphere of brain was homogenized in H-Buffer (320 mM sucrose, $2 \mathrm{mM}$ EDTA, $20 \mathrm{mM}$ Tris- $\mathrm{HCl}$ (pH 7.4), $1 \mathrm{mM}$ PMSF, $5 \mu \mathrm{g} / \mathrm{ml} \mathrm{leu-}$ peptin, $5 \mu \mathrm{g} / \mathrm{ml}$ aprotinin) for $\mathrm{A} \beta$ ELISA and immunoblots. Another hemisphere of brain was processed for immunohistochemical detection. Dissected brains were immersed in $4 \%$ formaldehyde for $18 \mathrm{~h}$ at $4{ }^{\circ} \mathrm{C}$, then cryoprotected in sucrose before being sectioned into $30 \mu \mathrm{m}$ thick free-floating sections. Sections were blocked in blocking buffer (PBS with $3 \%$ normal donkey serum, $1 \%$ bovine serum albumin (BSA) and $0.3 \%$ Triton X-100) for $60 \mathrm{~min}$ and incubated overnight at $4{ }^{\circ} \mathrm{C}$ in antibody dilution buffer (PBS with $1 \%$ normal donkey serum, $1 \%$ BSA and $0.3 \%$ Triton X-100) with primary antibodies, including mouse monoclonal anti-GFAP antibody (1:300, Millipore) and anti-A $31-16$ antibody (AB10, 1:300, Millipore), goat antiIba-1 antibody (1:300, abcam). Sections were then incubated in antibody dilution buffer containing Hoechst33258 (Invitrogen, $2 \mu \mathrm{g} / \mathrm{ml}$ ), Fluorescein isothiocyanateconjugated donkey anti-mouse IgG and RRX-conjugated donkey anti-rabbit IgG or Alexa Fluor 647-conjugated donkey anti-goat IgG (1:300; Jackson ImmunoResearch) in the dark for $2 \mathrm{~h}$ at room temperature. Sections were then washed with PBS containing $0.01 \%$ Triton X-100 and mounted with Aqua Poly/Mount (Polyscience Inc., Warrington, PA, USA). Fluorescent images of immunohistochemistry and ThS staining were taken using a Zeiss LSM 780 confocal microscopy (Jena, Germany). Amyloid plaque deposition was quantified using ImageJ software. The amyloid plaque burden indicates the AB10-reactive or ThS-positive area normalized to the total area. 
For detection of BrdU-positive cells, tissue sections were incubated in $10 \mathrm{mM}$ sodium citrate $(\mathrm{pH}$ 6.0) at $80{ }^{\circ} \mathrm{C}$ for $30 \mathrm{~min}$, and subsequently in $2 \mathrm{M} \mathrm{HCl}$ at $37^{\circ} \mathrm{C}$ for $30 \mathrm{~min}$. The sections were then incubated in blocking buffer and antibody dilution buffer with primary antibodies, including mouse monoclonal antibodies to BrdU (1:500, Senta Cruz) and rabbit polyclonal antibody to doublecortin (DCX, 1:500, abcam), and corresponding secondary antibodies, as mentioned above. The number of BrdU- or DCX-positive in the subgranular zone (SGZ) of dentate gyrus was quantified and revealed as the linear density of BrdU- or DCX-positive cells per millimeter of SGZ.

\section{Quantification of ThS- and AB10-stained plaques}

The quantification of ThS- and AB10-stained plaques was conducted individually. At least 3 coronal brain sections from each mouse were used for analysis. Each image was adjusted to the threshold for pixel detection (threshold setting for ThS-positive signal is 60; threshold setting for AB10-positive signal is 40). To eliminate background, particle less than 100 pixels (approximately $70 \mu \mathrm{m}^{2}$ ) was excluded. Occupied area by ThS- or AB10stained signal was divided by the full area of interest, including cortex and hippocampus, and represented as percentage.

\section{Mesurement of $A \beta_{1-42}$ levels}

Two-step sequential extraction of the brain $A \beta$ using $2 \%$ SDS and $70 \%$ formic acid (FA; Sigma) was processed as described previously [20]. Briefly, cortical homogenate was mixed with equal volume of $4 \%$ SDS in H-buffer containing protease inhibitor. The sample was then sonicated and centrifuged at $100,000 \times g$ for $60 \mathrm{~min}$ at $4{ }^{\circ} \mathrm{C}$. The supernatant was considered SDS-soluble fraction. The SDS-insoluble pellet was further resuspended in $70 \% \mathrm{FA}$ and centrifuged at $100,000 \times g$ for $60 \mathrm{~min}$ at $4{ }^{\circ} \mathrm{C}$. The supernatant was collected and neutralized with $1 \mathrm{M}$ Tris, $\mathrm{pH}$ 11. SDS-soluble and SDS-insoluble fractions were stored at $-80{ }^{\circ} \mathrm{C}$ until sandwich ELISA analysis. $\mathrm{A} \beta$ level was measured by a sensitive fluorescence based sandwich ELISA assay using a kit (Human $\beta$ - Amyloid 1-42, Invitrogen KHB3442). The detailed experiments were performed according to the manufacturer's protocol.

\section{Immunoblots}

For Western blot analysis, samples (30 $\mu$ g protein) were separated by sodium dodecyl sulfate-polyacrylamide gel electrophoresis and were then transferred to PVDF membranes. The primary antibodies used were as follows: rabbit anti-Iba-1 antibody (Wako), rabbit anti-NGF antibody, rabbit anti-GFAP antibody, mouse anti-APP antibody, rabbit anti-CTF antibody, rabbit anti-NEP antibody, rabbit anti-IDE antibody (Millipore) and mouse anti- $\beta$-actin antibody (Novus Biologicals). The secondary antibodies were anti-rabbit IgG antibody conjugated with horseradish peroxidase (HRP; GE Healthcare) and anti-mouse IgG antibody conjugated with HRP (Jackson ImmunoResearch). Enhanced chemiluminescence detection reagents (GE Healthcare) were used for detection. Bands were quantified using Fujifilm LAS-3000 Luminescent Image Analyzer (Tokyo, Japan).

\section{Nesting test}

After oral gavage administration for 81 days, mice were assessed for nesting task as described previously [21]. Two nestlets (approximately $5 \mathrm{~g}$ ) were placed into cage at $1 \mathrm{~h}$ before dark cycle, and then the nest score and the weight of unshredded nestlets were determined after overnight. The nest quality was assessed on a 1-5 rating scale, with 1 , nestlet was not noticeable touched; 2 , nestlet was partially shredded and scattered on the floor; 3, nestlet was mostly shredded but only flat nest was build; 4 , nest was identifiable but flat; and 5 , nest was build in a burrow.

\section{Statistical analysis}

The results are expressed as the mean \pm standard deviation (S.D.) and were analyzed by analysis of variance (ANOVA) with post-hoc Bonferroni multiple comparisons tests.

\section{Results}

HE-My and HE-Et reduce the number of AB10-stained plaque in cerebral cortex and hippocampus of APP/PS1 mice

In APP/PS1 transgenic mice model, plaques are well established and visible at 6 months old. Therefore, 5 months-old APP/PS1 mice were fed with $300 \mathrm{mg} / \mathrm{kg} /$ day HE-My or HE-Et for 30 days to explore their effects on plaque burden by double staining with AB10-antibody and ThS to observe the structure of whole plaque and its compact core, respectively. The number of AB10-stained plaque with diameter bigger than 100 pixel $(68 \mu \mathrm{m})$ in cerebral cortex and hippocampus of APP/PS1 mice were counted.

The treatment did not significantly change the body weight, suggesting that these treatments have no obvious side effect (data not shown). However, the number and burden of whole plaque stained by AB-10, but not compact core stained by ThS, were significantly reduced after 30-day administration of HE-My or HE-Et (Fig. 2a and b). Compared with vehicle-treated mice, HE-My treatment decreased burden and number of whole plaque by $38.6 \pm 9.3 \%$ and $34.8 \pm 13.4 \%$, respectively. More effectively, HE-Et treatment decreased burden and number of whole plaque by $55.8 \pm 15.2 \%$ and $43.5 \pm$ $15.6 \%$, respectively. 


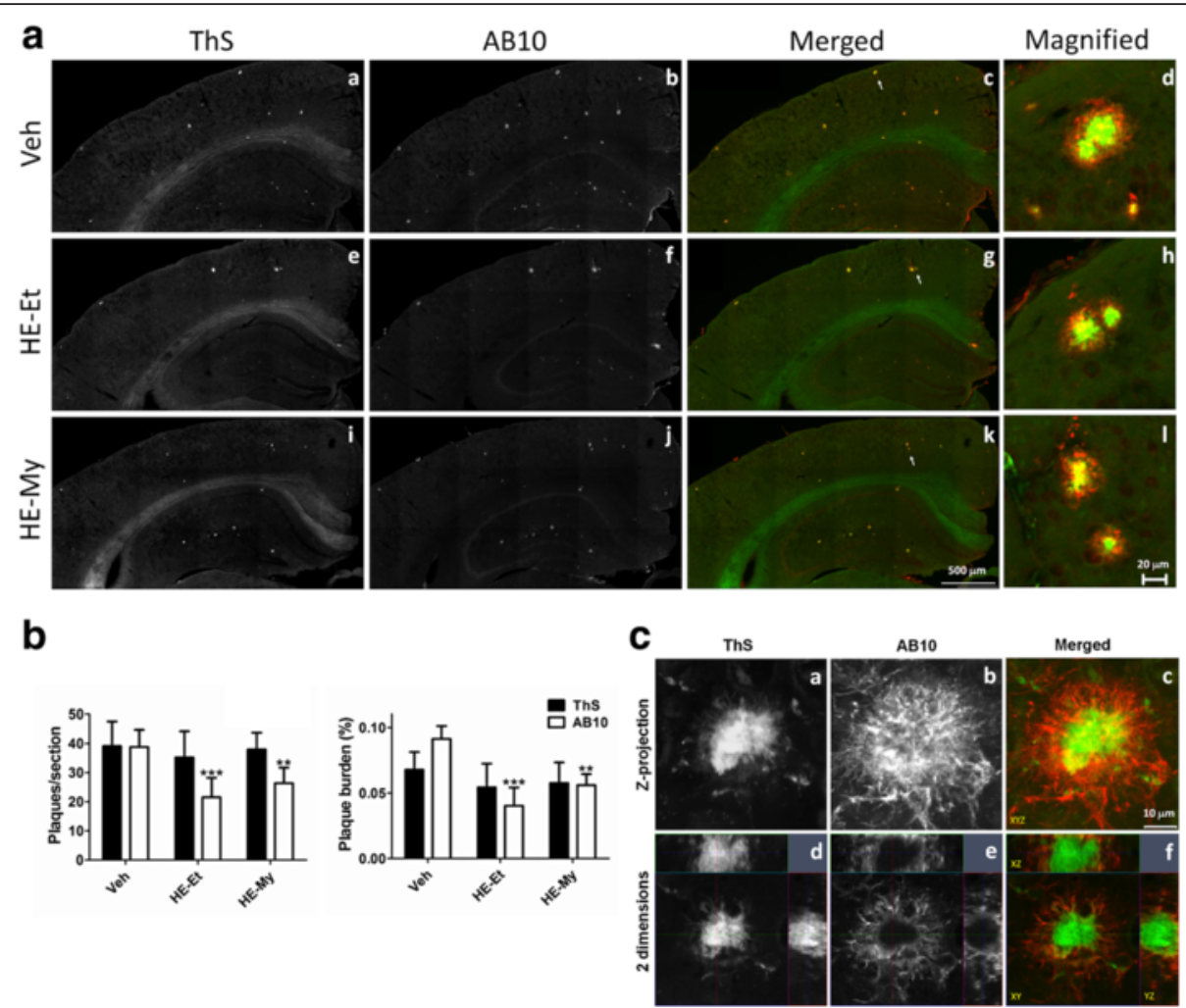

Fig. $2 \mathrm{HE}-\mathrm{Et}$ and HE-My reduce amyloid plaque burden in the area include the cerebral cortex and hippocampus of APP/PS1 mice. Five month-old APP/PS1 mice were orally administered with vehicle $(V e h, n=6)$, HE-Et $(n=5)$ and HE-My $(n=6)$ for 30 days. A. The representative fluorescent images of amyloid plaques detected by thioflavin S (ThS) staining (white in a, e and i, and green in c, d, g, h, k and I) and immunohistochemical staining with AB-10 antibody (white in $b, f$ and $j$, red in $c, d, g, h, k$ and $I$ ) in the area including parietal cortex and hippocampus. Sale bar: $500 \mu m$. A typical plaque is magnified and shows in the right side of each image. Sale bar: $20 \mu \mathrm{m}$. B. shows both the plaque number and burden in ThS- and AB-10-stained semi-cerebral sphere calculated by image analysis software. Plaque burden is displayed as a percentage of the area occupied by ThS- or AB-10-stained signal in the full area of interest. C. The structure of amyloid plaque in the cerebral cortex of APP/PS1 mice. The amyloid plaque in cerebral cortex of 6 months-old APP/PS1 mice was detected by ThS-staining (white in a and d, and green in c and f) and immunohistochemical staining with AB-10 antibody (white in $\mathrm{b}$ and $\mathrm{e}$, and red in $\mathrm{c}$ and $\mathrm{f}$ ). Upper panels show the representative Z-projection ( 3 dimensions, $\mathrm{XYZ}$, A-C) of a typical plaque. Lower panels show the 2 dimensional images $(X Y, X Z$, and $Y Z, D-F)$. The image indicated by arrow indicated the putative plaque unit. Sale bar: $10 \mu \mathrm{m}$. Single fluorescent images were presented as grayscale to enhance resolution

To identify the detail structure of whole plaque and its compact core, the image of the double stained plaques were displayed in both maximum projection of 3-dimensional stack (Fig. 2C, a-c) and confocal cross sections in $x y, y z$, and $x z$ (Fig. $2 \mathrm{C}, \mathrm{d}-\mathrm{f}$ ). The result showed that a typical plaque was composed by a ThSstained compact core and an AB10-imunostained filamentary structure, which surround the compact core.

\section{HE-My and HE-Et reduce the size of AB10-stained plaque in cerebral cortex and hippocampus of APP/PS1 mice}

Sixty double stained plaques of the representative slice of vehicle- and HE-Et-treated mice were selected by size to reveal the difference of plaque conformation (Fig. 3a). The result showed that the non-compact structure of plaques was significantly reduced by the treatment of HE-Et. A scatter plot of the plaque size in $\mu^{2}$ with compact core
(ThS-staining) against whole plaque (AB-10-staining) was plotted to reveal the morphological alteration of an individual plaque before and after HE-Et treatment. The result showed that the HE-Et modulated structure confined in the AB10-stained non-compact part of whole plaque but not the ThS-stained compact core (Fig. 3b). The similar result was found in the HE-My treated mice (data not shown).

For examining the involvement of $A \beta_{1-42}$ in the plaque structure, soluble and insoluble $A \beta$ were isolated from the cortex of APP/PS1 mice and the A $\beta$ level was detected using $A \beta_{1-42}$-ELISA analysis (Fig. $3 c$ ). The results showed that administration of HE-My significantly reduced the level of soluble, but not insoluble $A \beta_{1-42}$. Alternatively, no significant effect of HEEt on the level of both soluble and insoluble $A \beta$ was observed. 

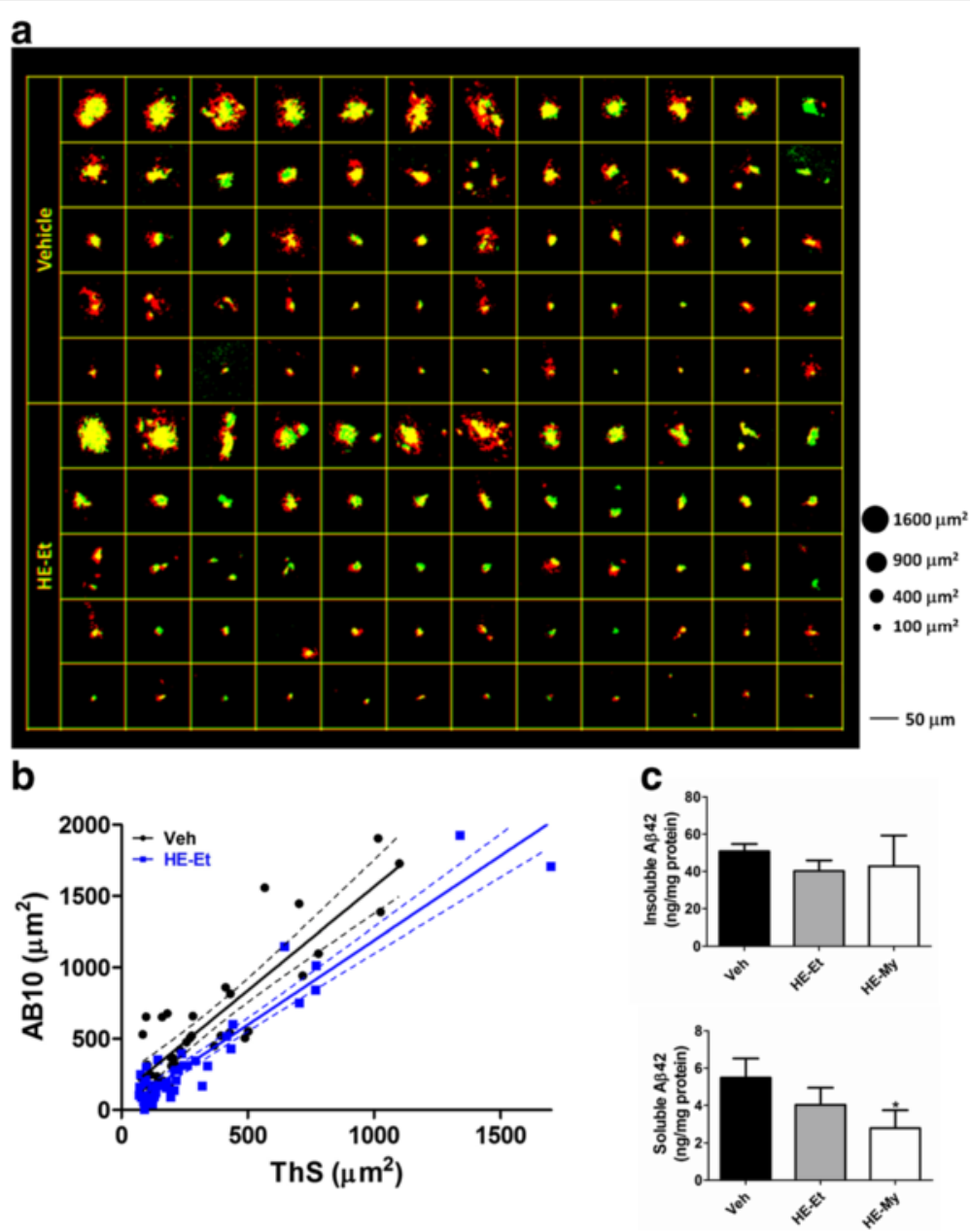

Fig 3 HE-Et reduces size of AB-10-stained plaque in the area including cerebral cortex and hippocampus of APP/PS1 mice. a. The representative images of ThS (green)- and AB-10 (red)-stained plaques (60 for each) selected in order of decreasing size from the area include the cerebral cortex and hippocampus of vehicle- and HE-Et-treated APP/PS1 mice. $\mathbf{b}$. A scatter plot of ThS- and AB-10-stained areas from representative samples with vehicle and HE-Et treatments (solid lines: linear regression lines; dashed lines: $95 \%$ confidence intervals; $R^{2}=0.8224$ for vehicle and $R^{2}=0.9079$ for HE-Et). $\mathbf{c}$. The levels of soluble and insoluble AB1-42 determined by ELISA. The results are the mean \pm S.D. Significant differences between treated and control (Veh) groups are indicated by *, $p<0.05$

\section{$\mathrm{HE}-\mathrm{Et}$ and $\mathrm{HE}-\mathrm{My}$ reduce $\mathrm{A} \beta$-associated glial cells in APP/PS1 mice}

Next, we evaluated the effects of HE-Et and HE-My on plaque-associated clusters of activated microglia and reactive astrocytes by immunohistochemical staining with AB-10, Iba-1 and GFAP antibodies, respectively. The image revealed that both the activated astrocyte and microglia formed cluster surrounding plaque in the area including cortex and hippocampus (Fig. 4a and b). HE-Et treatment decreases the number of Iba-1-positive microglia cluster and GFAP-positive astrocyte cluster by $25.2 \pm$ $9.4 \%$ and $40.0 \pm 13.5 \%$, respectively (Fig. 4c). HE-My treatment decreases the number of microglia and astrocyte cluster by $19.4 \pm 13.9 \%$ and $43.3 \pm 9.0 \%$, respectively (Fig. 4c). To determine the total reducing of microglia activation and astrocytes reactivity by HE-My and HE-Et, the cortex homogenates of the treated mice were examined by immunoblot using anti-Iba-1 and anti-GFAP antibodies. The result showed that the level of microglia activation was decreased by HE-Et and HE-My to $47.9 \pm 12.9 \%$ and $37.9 \pm 7.9 \%$ of control, respectively (Fig. 4d). In contrast, the level of astrocytes reactivity was reduced to $64.3 \pm 12.1 \%$ and $55.7 \pm 20.8 \%$ of control.

\section{HE-Et and HE-My promote the level of $A \beta$ degrading protein in cortex of APP/PS1 mice}

To understand the mechanisms by which HE-Et and HEMy reducing A $\beta$ plaque in APP/PS1 mice, we assessed the proteins involving APP processing and $\mathrm{A} \beta$ degradation. 


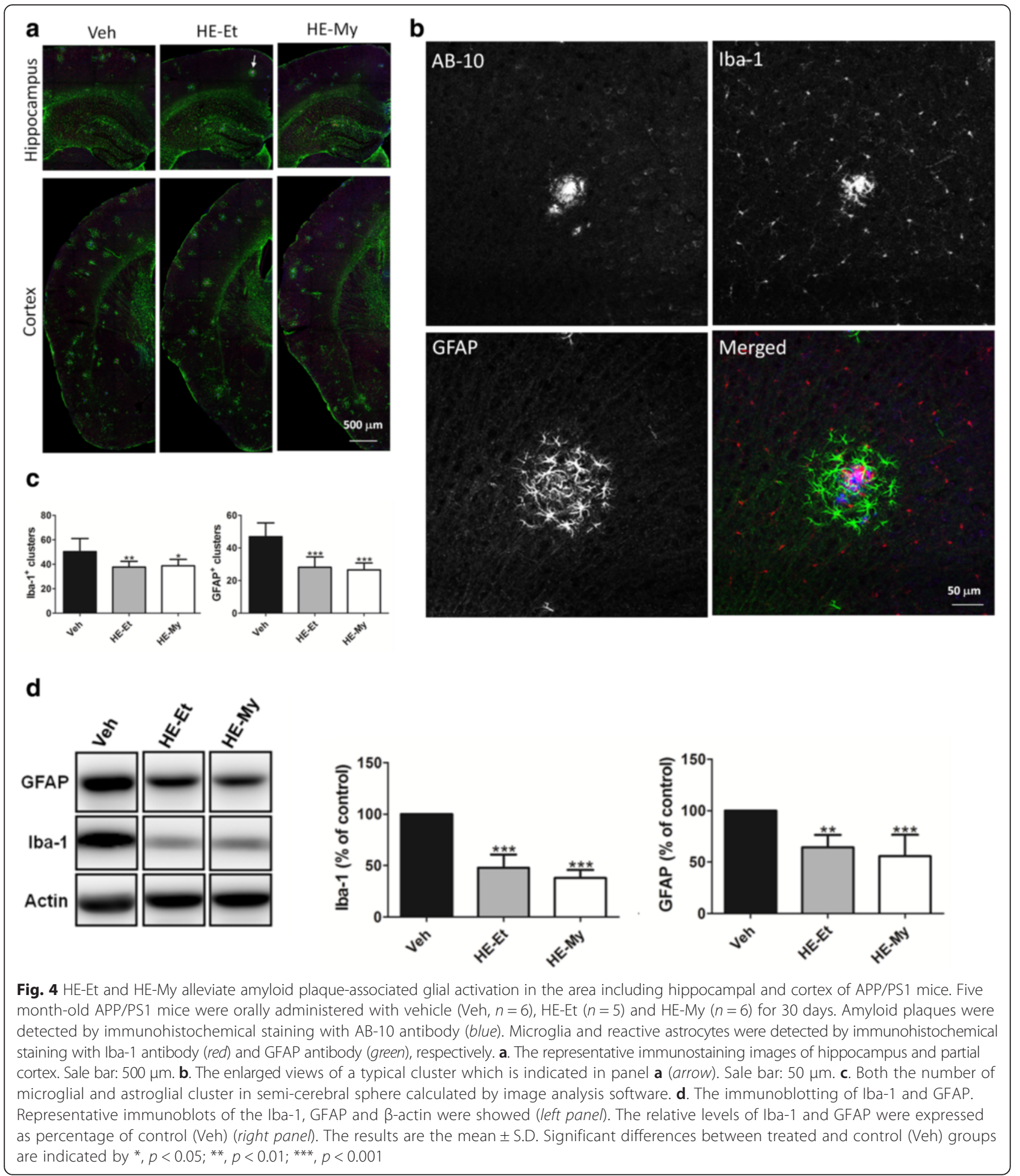

APP processing was examined by the levels of full length APP, and C-terminal fragments (CTF)- $\alpha$ and CTF- $\beta$. The result revealed that HE-Et and HE-My treatment did not affect the levels of APP, CTF- $\alpha$ and CTF- $\beta$. Next, we detected the levels of $A \beta$ degrading enzymes including IDE and neprilysin. The result showed that HE-Et and HE-My treatment increased the level of IDE in cortex by $127.7 \pm 81.4 \%$ and $103.9 \pm$ $30.9 \%$, respectively (Fig. 5a). However, no effect on the level of neprilysin was observed. 


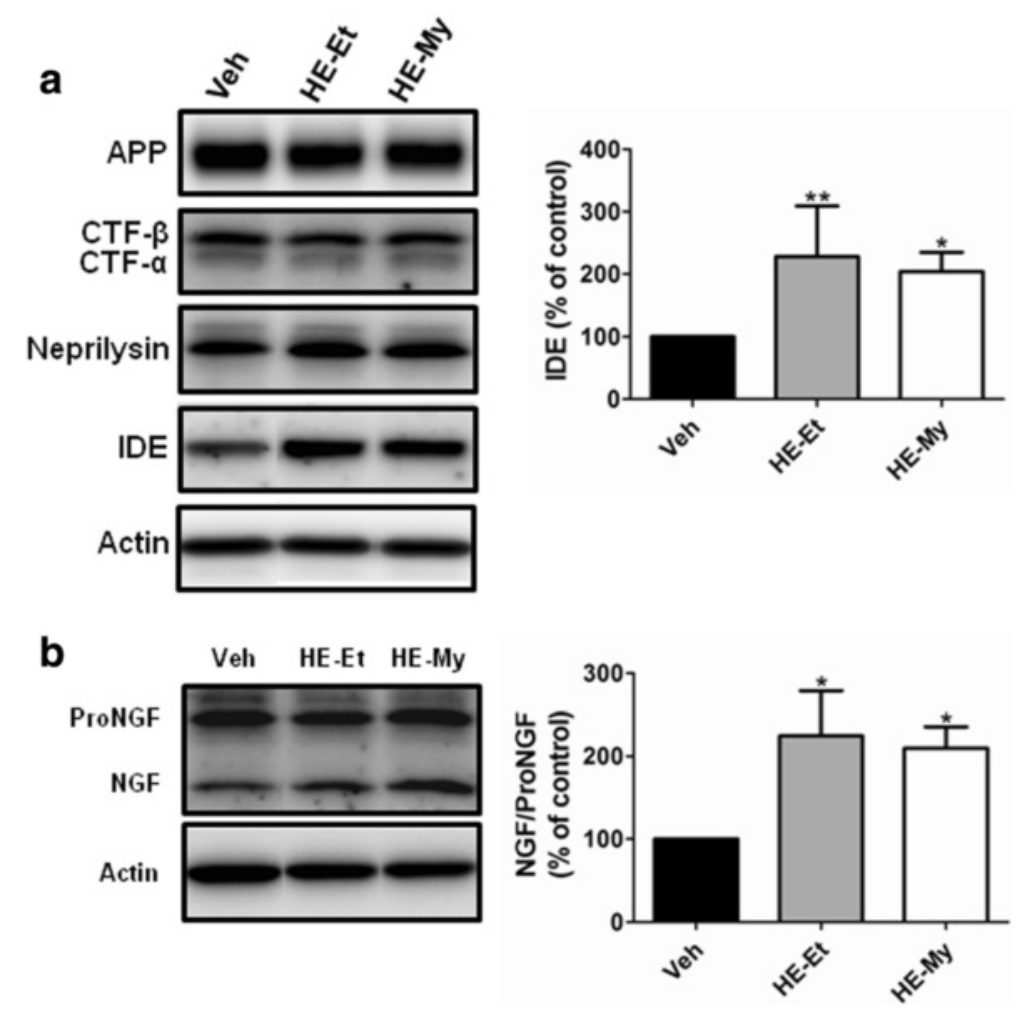

Fig 5 Effects of HE-Et and HE-My on the level of the proteins regulating A 3 accumulation and the level of NGF in cerebral cortex of APP/PS1 mice. Five months-old APP/PS1 mice were orally administered with vehicle $(V e h, n=6)$, HE-Et $(n=5)$ and HE-My $(n=5)$ for 30 days. Cortex was removed and homogenized, and the proteins involving in amyloidogenesis and amyloid clearance and NGF maturation in lysates were analyzed by immunoblotting. a The representative immunoblots of APP, CTF- $\alpha,-\beta$, IDE, neprilysin and $\beta$-actin (left pane). The level of APP, CTF- $\alpha$ and $-\beta$, IDE and neprilysin was presented as percentage of control (Veh) (right panel). b The representative immunoblots of the proNGF, NGF and $\beta$-actin (left panel). The relative level of NGF/proNGF ratio was presented as percentage of control (Veh) (right panel). The results are the mean \pm S.D. Significant differences between treated and control (Veh) groups are indicated by ${ }^{*}, p<0.05 ;{ }^{*}, p<0.01$

HE-Et and HE-My increase NGF/proNGF ratio and promote hippocampal neurogenesis in APP/PS1 mice

The levels of NGF and proNGF were analyzed by immunoblotting. HE-Et and HE-My significantly increase NGF/proNGF ratio by $124.7 \pm 54.1 \%$ and $109.9 \pm 25.7 \%$, respectively (Fig. 5b).

We hypothesized that the increased NGF/proNGF ratio and declined microglial activation may promote hippocampal neurogenesis. Therefore, newly born granular neurons and proliferating type 2 progenitors in the subgranular zone (SGZ) was assessed by immunohistochemical staining using anti-DCX and anti-BrdU antibody, respectively. We found that the number of both newly born granular neurons (DCX-positive) and proliferating type 2 progenitors (BrdU-positive) were declined in APP/PS1 mice as compared with the wild type mice (Fig. 6). However, the declined number of the DCX-, BrdU-, and BrdU/DCX-double positive neurons were recovered after the treatment of HE-My and HE-Et.
HE-My recovers activity of daily living decline in APP/PS1 mice

Nesting behaviors engage a broad network of brain regions; have previously been applied on evaluating the daily living skills of AD transgenic mice. Therefore, nesting task was performed. The result showed that APP/PS1 mice had lower nesting score and less nestlet shredding than WT mice. However, HE-My-treated APP/PS1 mice recovered the decline of both nesting score (Fig. 7a and b) and nestlet shredding (Fig. 7a and c).

\section{Discussion}

Our results reveal that the administrations of HE-Et or HE-My to APP/PS1 mice for 30 days eliminated amyloid plaque burden, prevented recruitments and activations of plaque-associated microglia and astrocytes, promoted the expression of IDE, the NGF/proNGF ratio, and the proliferation of neuron progenitors and the number of newly born neurons in dentate gyrus. Finally, we found that the administrations of HE-My for 81 days recovered 

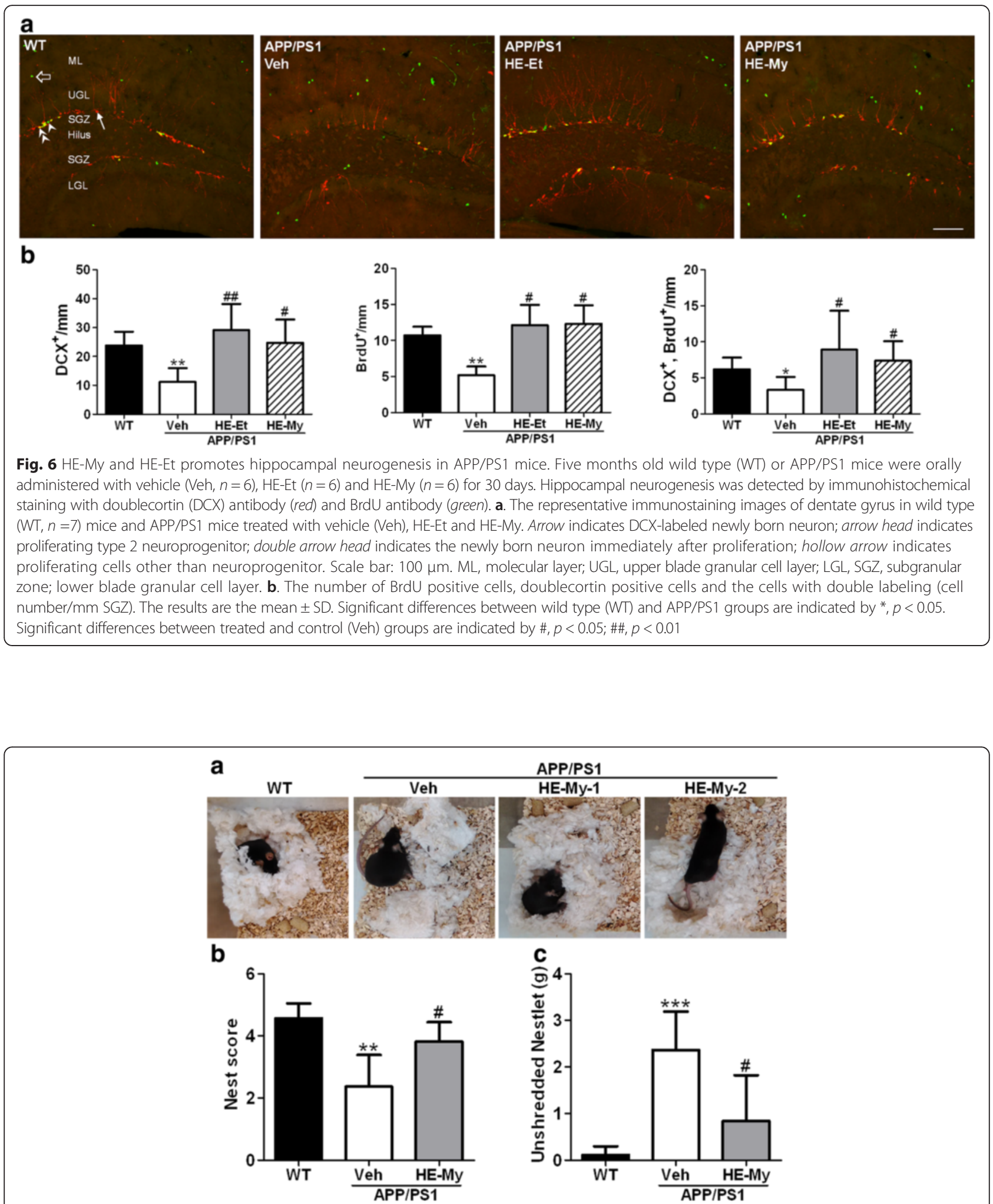

Fig. 7 The deficit on nest construction displayed by APP/PS1 mice were improved by HE-My treatment. Five months old wild type (WT) or APP/PS1 mice were orally administered with vehicle $($ Veh, $n=6)$ or HE-My $(n=6)$ for 81 days and then nest construction test were performed. The representative images of the nest construction (a), the nest score $(\mathbf{b})$ and unshredded nestlet (c) were shown. The results are the mean \pm SD. Significant differences between WT $(n=8)$ and APP/PS1 groups are indicated by ${ }^{*}, p<0.01 ; * *, p<0.001$. Significant differences between treated and control (Veh) groups are indicated by $\#, p<0.05$ 
the deficits on activity of daily living skills in APP/PS1 mice.

Our previous study shows that $300 \mathrm{mg} / \mathrm{kg}$ HE-My display the best/highest neuroprotective activity against ischemia reperfusion injury [22]. The safe dose of erinacine A-enriched Hericium erinaceus was as high as $3000 \mathrm{mg} / \mathrm{kg}$ in a 28-day oral feeding study in SpragueDawley rats [17]. Furthermore our previous report showed that $30 \mathrm{mg} / \mathrm{kg}$ erinacine A and S process similar activity to reduce $A \beta$ deposition and increase IDE expression [18]. HE-My and HE-Et contain $19 \mathrm{mg} / \mathrm{g}$ and $104.4 \mathrm{mg} / \mathrm{g}$ of HE-A, respectively. Hence, it is likely that the ingredients form HE-My or HE-Et process similar activity and HE-My or HE-Et (300 mg/kg/day) reach ceiling effect on $\mathrm{A} \beta$ clearance. Therefore, we chose $300 \mathrm{mg} / \mathrm{kg}$ to test its effect.

Previous reports show that female APP/PS1 mice have more deposition of amyloid plaque than that of male APP/PS1 mice [23-25], and both male and female APP/PS1 mice reveal the similar impairment in spatial learning and memory [23]. Additionally, both genders reveal good activity to build nest $[26,27]$. Therefore, we think female APP/PS1 mice is also suitable as a model to evaluate the effect of treatment on AD-like pathology.

Previous studies showed that $H$. erinaceus mycelia and its components possess the activity to stimulate NGF expression and secretion in vitro and in vivo [10]. In our present study, it is evidenced that HE-My and its components increase the NGF/proNGF ratio (Fig. 5b). Recent studies pointed out that the NGF metabolic dysfunction is associated with $\mathrm{AD}$ and Down syndrome [28]. Mature NGF is derived from proNGF by some convertases, such as plasmin and furin, and degraded by matrix metalloprotease 9 . However, it is still unclear whether $H$. erinaceus mycelia and its components induce the expression of plasmin and furin, or reduce the expression of MMP-9.

The structure of amyloid plaque [29] and the sequential clustering of plaque-associated activated microglia and reactive astrocytes [30] have been studied by some previous works. Those works suggested that the accumulation of $A \beta$ may lead to abnormal neuroinflammation and oxidative stress, and the microglial activation is highly associated with the accumulation of $A \beta$. In our present study, it is evident that the glial cluster is constructed by at least four sequential layers (i.e. amyloid compact core with radiating arm; amyloid none $\beta$-pleated sheet filamentary structure; microglial clustering; and astroglial clustering) (Figs. 2c and 4b). The activity of HE-My and HE-Et to reduce the filamentary structure of amyloid plaque burden in both cortex and hippocampus is a novel finding.

Although $A \beta$ staining by both ThS and AB10 cannot functionally distinguish between increased phagocytosis and impaired degradation, our results showed that
HE-My and HE-Et substantially altered the characteristics of $\mathrm{A} \beta$ plaque deposition in the APP/PS1 mice (Figs. 2 and 3). HE-My and He-Et significantly reduced the non-compact structure of amyloid plaque (Fig. 3b). Additionally, HE-My-treated APP/PS1 mice showed a $40 \%$ reduction in brain concentrations of soluble forms of $\mathrm{A} \beta_{1-42}$ (Fig. 3c).

$\mathrm{AD}$ is characterized by elevated levels of $\mathrm{A} \beta$ that are produced by $\beta$ - and $\gamma$-secretases [31]. As a corollary, any approach aimed at blocking the production of $A \beta$ by interfering with these enzymes could be seen as a valid therapeutic strategy. On the other hand, activation of $\alpha$-secretase is another strategy to block the production of $\mathrm{A} \beta$. In our present study, HE-My and HE-Et attenuated the AB10-stained non-compact plaque structure and reduced the level of soluble form $A \beta_{1-42}$ may be attributable to the inhibition of $\beta$ - or $\gamma$-secretase or activation of $\alpha$-secretase. For determining this effect, the levels of APP, CTF- $\alpha$ and $-\beta$ were measured. However, the outcome was negative. However, HE-Et and HE-My were found to promote IDE expression suggesting that $A \beta$ clearance by degradation might be involved in the $A \beta$ reduction effect. IDE is the degrading enzyme for $A \beta$ and APP intracellular domain (AICD) [32, 33]. IDE is located in the cytosol and mitochondria [34], and a small proportion of IDE also secreted out from cells [35]. Agonists of the PPAR $\gamma$ pathway have been shown to enhance $A \beta$ clearance by a mechanism that appeared to implicate IDE. Moreover, Notch signaling pathway may also regulate IDE expression [36]. The data establishing an involvement of IDE in $A \beta$ degradation in vivo are very strong. Hence, up-regulation of IDE activity remains to be a therapeutic choice [37]. IDE knockout mice and rat with partial loss-of-function mutations in IDE reveal cerebral $\mathrm{A} \beta$ accumulation by $50 \%$ [38]. In contrast, previous work demonstrated that two-fold increase of IDE via transgenic over-expression reduces obviously $50 \% \mathrm{~A} \beta$ deposition in APP transgenic mice [37]. Therefore, it is likely that the two-fold increase of IDE expression after HE-My or HE-Et treatment may attenuate amyloid plaque burden. It has been reported that with age or after some insults, level of IDE in the brain reduce significantly [39]. In our present study, APP/PS1 transgenic mice, IDE was up-regulated as compared to the wild type mice (Data not shown). This result is consistent with the previous report that in APPswe/PSEN1(A246E) transgenic mice, IDE was up-regulated by $\mathrm{A} \beta[40]$.

Recent evidence suggests that impaired clearance may be the driving force behind sporadic $\mathrm{AD}$ [41]. In addition to phagocytosis, microglia also contribute to $A \beta$ clearance through proteolytic enzymes, including IDE and neprilysin [42]. In the present study, we found that HE-My and HE-Et promote IDE expression, suggesting that $\mathrm{A} \beta$ clearance by IDE degradation may be involved in the $A \beta$ reduction 
effect. PPAR $\gamma$ pathway and Notch signaling have been found to enhance IDE expression in neurons [43, 44]. However, more study is required to reveal the mechanism mediates HE-My and HE-Et promoted IDE expression.

HE-My and HE-Et were found to promote hippocampal neurogenesis (Fig. 6). Recent study found that APP could function to influence neurogenesis via its two separate domains, sAPP $\alpha$ and AICD. The sAPP $\alpha$ was shown to be neuroprotective and important to neurogenesis, whereas AICD was found to negatively modulate neurogenesis [45]. In our present study, however, administration of HE-Et and HE-My did not significantly decreased the level of CTF- $\alpha$ and CTF- $\beta$, which are substrates for $\gamma$-secretase to produce AICD. Therefore, neurogenesis may not be promoted by the decrease of AICD after the administration of HE-Et or HE-My. On the other hand, inflammatory challenge triggered by $A \beta$ induces the production of proinflammatory cytokines by microglia as well as resident astrocytes have profound detrimental effects on adult neurogenesis [46].

We focus on species-specific nest building activity because those are spontaneous hippocampus-dependent behaviors [21] that have been proposed to be equivalent to activities of daily living (ADL) skills in humans [47], and the loss of ADL skills is the warning sign of $\mathrm{AD}$ in clinical [48]. Moreover, the deficits in nesting behaviors have been shown in APP/PS1 mice $[26,49]$ and Tg2576 transgenic mice [50]. In our unpublished data, HE-Et or erinacine $\mathrm{A}$ also improved the nesting behavior with similar activity. Besides in hippocampus, nesting tests are sensitive to lesions in medial prefrontal cortex and various regions including septum, respectively $[21,26]$. We found that HE-My restored nesting behavior (Fig. 7), suggesting that HE-My may improve the impairment in multiple brain regions in APP/PS1 mice.

\section{Conclusion}

Our results suggested that HE-My reduced cortical and hippocampal amyloid plaque burden through increasing the level of IDE, and increase NGF maturation and hippocampal neurogenesis in APP/PS1 mice. We also show that HE-My recovers behavioral deficits in APP/PS1 mice. These findings raise the possibility that HE-My may have therapeutic potential for treating $\mathrm{AD}$ as well as the other neurodegenerative diseases.

\footnotetext{
Abbreviations

$A D$, Alzheimer's disease; $A D L$, activities of daily living; AICD, APP intracellular domain; APP, amyloid precursor protein; APP/PS1, APPswe/PS1 $\triangle E 9 ; A \beta, \beta$-amyloid peptide; BDNF, brain derived neurotrophic factor; BrdU, 5-bromo-2'-deoxyuridine; CTF, C-terminal fragment; DCX, doublecortin; FA, formic acid; HE-Et, ethanol extracts of HE-My; HE-My, H. erinaceus mycelia; IDE, insulin-degrading enzyme; $\mathrm{MCl}$, mild cognitive impairment; NGF, nerve growth factor; proNGF, NGF precursor; PS1, presenilin 1; SGZ, subgranular zone; ThS, thioflavin S; WT, wild type
}

\section{Acknowledgments}

The design of the study was supported by Biotechnology Center, Grape King Bio Ltd. Chung-Li, Taoyuan 320, Taiwan, R.O.C. The collection, analysis, interpretation of data and manuscript writing of this study was supported by the Ministry of Science and Technology (MOST 103-2320-B-077-004-MY3; MM10501-0274).

\section{Availability of data and materials \\ The dataset(s) supporting the conclusions of this article are not shared because of that the patent application is ongoing.}

\section{Authors' contributions \\ TTा performed the experiments and data analysis, and participated in the drafted manuscript, C-CC, LYL and WPC participated in ferment of H. erina- ceus mycelia. C-CC, CKL and CCS performed the isolation and component identification of $H$. erinaceus mycelia. CYH and YJS participated in its design and coordination and helped to draft the manuscript. All authors read and approved the final manuscript.}

\section{Competing interests}

The authors declare that they have no competing interests.

\section{Consent for publication}

Not applicable.

\section{Ethics approval and consent to participate}

This research does not involve human subjects, human material, or human data. The Institutional Animal Care and Use Committee at the National Research Institution of Chinese Medicine approved the animal protocol (IACUC No: 100-A-04 and 102-417-3).

\section{Author details}

${ }^{1}$ Institute of Biopharmaceutical Science, National Yang-Ming University, Taipei 112, Taiwan, Republic of China. ${ }^{2}$ Biotechnology Center, Grape King Bio Ltd. Chung-Li, Taoyuan 320, Taiwan, Republic of China. ${ }^{3}$ National Research Institute of Chinese Medicine, Ministry of Health and Welfare, Taipei 112, Taiwan, Republic of China. ${ }^{4}$ Department of Biotechnology and Department of Nursing, HungKuang University, Taichung 433, Taiwan, Republic of China. ${ }^{5}$ Ph.D Program for the Clinical Drug Discovery from Botanical Herbs, College of Pharmacy, Taipei Medical University, Taipei 110, Taiwan, Republic of China.

Received: 19 February 2016 Accepted: 15 June 2016

Published online: 27 June 2016

\section{References}

1. Hardy J, Selkoe DJ. The amyloid hypothesis of Alzheimer's disease: progress and problems on the road to therapeutics. Science. 2002;297:353-6.

2. Haass C, Kaether C, Sisodia S, Thinakaran G. Trafficking and proteolytic processing of APP. Cold Spring Harb Perspect Med. 2011;2:a006270.

3. Saido T, Leissring MA. Proteolytic degradation of amyloid $\beta$-protein. Cold Spring Harb Perspect Med. 2012;2:a006379.

4. Winner B, Winkler J. Adult neurogenesis in neurodegenerative diseases. Cold Spring Harb Perspect Biol. 2015;7:a021287.

5. Iulita MF, Cuello AC. Nerve growth factor metabolic dysfunction in Alzheimer's disease and Down syndrome. Trends Pharmacol Sci. 2014;35:338-48.

6. Cattaneo A, Calissano P. Nerve growth factor and Alzheimer's disease: new facts for an old hypothesis. Mol Neurobiol. 2012;46:588-604.

7. Scardigli R, Capelli P, Vignone D, Brandi R, Ceci M, La Regina F, Piras E, Cintoli S, Berardi N, Capsoni S, Cattaneo A. Neutralization of nerve growth factor impairs proliferation and differentiation of adult neural progenitors in the subventricular zone. Stem Cells. 2014;32:2516-28.

8. Sierra A, Beccari S, Diaz-Aparicio I, Encinas JM, Comeau S, Tremblay ME. Surveillance, phagocytosis, and inflammation: how never-resting microglia influence adult hippocampal neurogenesis. Neural Plast. 2014;2014:610343.

9. Phan CW, David P, Naidu M, Wong KH, Sabaratnam V. Therapeutic potential of culinary-medicinal mushrooms for the management of neurodegenerative diseases: diversity, metabolite, and mechanism. Crit Rev Biotechnol. 2015;35:355-68.

10. Mori K, Obara Y, Hirota M, Azumi Y, Kinugasa S, Inatomi S, Nakahata N. Nerve growth factor-inducing activity of Hericium erinaceus in $1321 \mathrm{~N} 1$ human astrocytoma cells. Biol Pharm Bull. 2008;31:1727-32. 
11. Shimboa M, Kawagishib H, Yokogoshi H. Erinacine A increases catecholamine and nerve growth factor content in the central nervous system of rats. Nutr Res. 2005;25:617-23.

12. Mori K, Obara Y, Moriya T, Inatomi S, Nakahata N. Effects of Hericium erinaceus on amyloid beta(25-35) peptide-induced learning and memory deficits in mice. Biomed Res. 2011;32:67-72.

13. Mori K, Inatomi S, Ouchi K, Azumi Y, Tuchida T. Improving effects of the mushroom Yamabushitake (Hericium erinaceus) on mild cognitive impairment: a double-blind placebo-controlled clinical trial. Phytother Res. 2009;23:367-72.

14. Lee JE, Han PL. An update of animal models of Alzheimer disease with a reevaluation of plaque depositions. Exp Neurobiol. 2013;22:84-95.

15. Volianskis A, Kostner R, Molgaard M, Hass S, Jensen MS. Episodic memory deficits are not related to altered glutamatergic synaptic transmission and plasticity in the CA1 hippocampus of the APPswe/PS1deltaE9-deleted transgenic mice model of $\beta$-amyloidosis. Neurobiol Aging. 2010;31:1173-87.

16. Savonenko A, Xu GM, Melnikova T, Morton JL, Gonzales V, Wong MP, Price DL, Tang F, Markowska AL, Borchelt DR. Episodic-like memory deficits in the APPswe/ PS1dE9 mouse model of Alzheimer's disease: relationships to beta-amyloid deposition and neurotransmitter abnormalities. Neurobiol Dis. 2005;18:602-17.

17. Li IC, Chen YL, Lee LY, Chen WP, Tsai YT, Chen CC, Chen CS. Evaluation of the toxicological safety of erinacine A-enriched Hericium erinaceus in a 28-day oral feeding study in Sprague-Dawley rats. Food Chem Toxicol. 2014;70:61-7.

18. Chen CC, Tzeng TT, Chen CC, Ni CL, Lee LY, Chen WP, Shiao YJ, Shen CC. Erinacine $\mathrm{S}$, a Rare Sesterterpene from the Mycelia of Hericium erinaceus. J Nat Prod. 2016;79:438-41. doi:10.1021/acs.jnatprod.5b00474.

19. Westermark GT, Johnson KH, Westermark P. Staining methods for identification of amyloid in tissue. Methods Enzymol. 1999;309:3-25.

20. Durairajan SS, Liu LF, Lu JH, Chen LL, Yuan Q, Chung SK, Huang L, Li XS, Huang JD, Li M. Berberine ameliorates beta-amyloid pathology, gliosis, and cognitive impairment in an Alzheimer's disease transgenic mouse model. Neurobiol Aging. 2012;33:2903-19.

21. Deacon RM. Assessing nest building in mice. Nat Protoc. 2006;1:1117-9.

22. Lee KF, Chen JH, Teng CC, Shen CH, Hsieh MC, Lu CC, Lee KC, Lee LY, Chen WP, Chen CC, Huang WS, Kuo HC. Protective effects of Hericium erinaceus mycelium and its isolated erinacine A against ischemia-injury-induced neuronal cell death via the inhibition of iNOS/p38 MAPK and nitrotyrosine. Int J Mol Sci. 2014;15:15073-89.

23. Gimbel DA, Nygaard HB, Coffey EE, Gunther EC, Laurén J, Gimbel ZA, Strittmatter SM. Memory impairment in transgenic Alzheimer mice requires cellular prion protein. J Neurosci. 2010:30:6367-74.

24. Burke RM, Norman TA, Haydar TF, Slack BE, Leeman SE, Blusztajn JK, Mellott TJ. BMP9 ameliorates amyloidosis and the cholinergic defect in a mouse model of Alzheimer's disease. Proc Natl Acad Sci U S A. 2013;110:19567-72.

25. Sehgal N, Gupta A, Valli RK, Joshi SD, Mills JT, Hamel E, Khanna P, Jain SC, Thakur SS, Ravindranath $\mathrm{V}$. Withania somnifera reverses Alzheimer's disease pathology by enhancing low-density lipoprotein receptor-related protein in liver. Proc Natl Acad Sci U S A. 2012;109:3510-5.

26. Filali M, Lalonde R. Age-related cognitive decline and nesting behavior in an APPswe/PS1 bigenic model of Alzheimer's disease. Brain Res. 2009:1292:93-9.

27. Wesson DW, Wilson DA. Age and gene overexpression interact to abolish nesting behavior in Tg2576 amyloid precursor protein (APP) mice. Behav Brain Res. 2011;216:408-13.

28. Budni J, Bellettini-Santos T, Mina F, Garcez ML, Zugno Al. The involvement of BDNF, NGF and GDNF in aging and Alzheimer's disease. Aging Dis. 2015; 6:331-341.

29. Liu Z, Condello C, Schain A, Harb R, Grutzendler J. CX3CR1 in microglia regulates brain amyloid deposition through selective protofibrillar amyloid-beta phagocytosis. J Neurosci. 2010;30:17091-101.

30. Serrano-Pozo A, Muzikansky A, Gomez-Isla T, Growdon JH, Betensky RA, Frosch MP, Hyman BT. Differential relationships of reactive astrocytes and microglia to fibrillar amyloid deposits in Alzheimer disease. J Neuropathol Exp Neurol. 2013;72:462-71.

31. Gandy S. Lifelong management of amyloid-beta metabolism to prevent Alzheimer's disease. N Engl J Med. 2012;367:864-6.

32. Leissring MA. The AbetaCs of Abeta-cleaving proteases. J Biol Chem. 2008;283:29645-9.

33. Edbauer D, Willem M, Lammich S, Steiner H, Haass C. Insulin-degrading enzyme rapidly removes the beta-amyloid precursor protein intracellular domain (AICD). J Biol Chem. 2002;277:13389-93.
34. Leissring MA, Farris W, Wu X, Christodoulou DC, Haigis MC, Guarente L, Selkoe DJ. Alternative translation initiation generates a novel isoform of insulindegrading enzyme targeted to mitochondria. Biochem J. 2004;383:439-46.

35. Zhao J, Li L, Leissring MA. Insulin-degrading enzyme is exported via an unconventional protein secretion pathway. Mol Neurodegener. 2009;4:4.

36. Leal MC, Surace El, Holgado MP, Ferrari CC, Tarelli R, Pitossi F, Wisniewski T, Castano EM, Morelli L. Notch signaling proteins HES-1 and Hey-1 bind to insulin degrading enzyme (IDE) proximal promoter and repress its transcription and activity: implications for cellular Abeta metabolism. Biochim Biophys Acta. 2012;1823:227-35.

37. Leissring MA, Farris W, Chang AY, Walsh DM, Wu X, Sun X, Frosch MP, Selkoe DJ. Enhanced proteolysis of beta-amyloid in APP transgenic mice prevents plaque formation, secondary pathology, and premature death. Neuron. 2003;40:1087-93

38. Farris W, Mansourian S, Leissring MA, Eckman EA, Bertram L, Eckman CB, Tanzi RE, Selkoe DJ. Partial loss-of-function mutations in insulin-degrading enzyme that induce diabetes also impair degradation of amyloid betaprotein. Am J Pathol. 2004;164:1425-34.

39. Cook DG, Leverenz JB, McMillan PJ, Kulstad JJ, Ericksen S, Roth RA, Schellenberg GD, Jin LW, Kovacina KS, Craft S. Reduced hippocampal insulin-degrading enzyme in late-onset Alzheimer's disease is associated with the apolipoprotein E-epsilon4 allele. Am J Pathol. 2003;162:313-9.

40. Vepsalainen S, Hiltunen M, Helisalmi S, Wang J, van Groen T, Tanila H, Soininen $\mathrm{H}$. Increased expression of Abeta degrading enzyme IDE in the cortex of transgenic mice with Alzheimer's disease-like neuropathology. Neurosci Lett. 2008:438:216-20.

41. Mawuenyega KG, Sigurdson W, Ovod V, Munsell L, Kasten T, Morris JC, Yarasheski KE, Bateman RJ. Decreased clearance of CNS beta-amyloid in Alzheimer's disease. Science. 2010;330:1774.

42. Malito E, Hulse RE, Tang WJ. Amyloid beta-degrading cryptidases: insulin degrading enzyme, presequence peptidase, and neprilysin. Cell Mol Life Sci. 2008;65:2574-85.

43. Du J, Zhang L, Liu S, Zhang C, Huang X, Li J, Zhao N, Wang Z. PPARgamma transcriptionally regulates the expression of insulin-degrading enzyme in primary neurons. Biochem Biophys Res Commun. 2009;383:485-90.

44. Edbauer D, Willem M, Lammich S, Steiner H, Haass C. Insulin-degrading enzyme rapidly removes the beta-amyloid precursor protein intracellular domain (AICD). J Biol Chem. 2002;277:13389-393.

45. Zhou ZD, Chan $\mathrm{CH}, \mathrm{Ma} \mathrm{QH}, \mathrm{Xu}$ XH, Xiao ZC, Tan EK. The roles of amyloid precursor protein (APP) in neurogenesis: Implications to pathogenesis and therapy of Alzheimer disease. Cell Adh Migr. 2011;5:280-92.

46. Sato K. Effects of Microglia on Neurogenesis. Glia. 2015;63:1394-405.

47. Jirkof P. Burrowing and nest building behavior as indicators of well-being in mice. J Neurosci Methods. 2014:234:139-46.

48. Galasko D, Bennett D, Sano M, Ernesto C, Thomas R, Grundman M, Ferris S. An inventory to assess activities of daily living for clinical trials in Alzheimer's disease. The Alzheimer's Disease Cooperative Study. Alzheimer Dis Assoc Disord. 1997;11 Suppl 2:S33-9.

49. Janus C, Flores AY, Xu G, Borchelt DR. Behavioral abnormalities in APPSwe/PS1dE9 mouse model of AD-like pathology: comparative analysis across multiple behavioral domains. Neurobiol Aging. 2015;36:2519-32.

50. Deacon RM, Cholerton LL, Talbot K, Nair-Roberts RG, Sanderson DJ, Romberg C, Koros E, Bornemann KD, Rawlins JN. Age-dependent and -independent behavioral deficits in Tg2576 mice. Behav Brain Res. 2008;189:126-38.

\section{Submit your next manuscript to BioMed Central and we will help you at every step:}

- We accept pre-submission inquiries

- Our selector tool helps you to find the most relevant journal

- We provide round the clock customer support

- Convenient online submission

- Thorough peer review

- Inclusion in PubMed and all major indexing services

- Maximum visibility for your research

Submit your manuscript at www.biomedcentral.com/submit 